\title{
Job Stress among Female Residents during Postgraduate Training at a University Hospital in Karachi, Pakistan
}

\author{
Hashmi, M., Khan, F.A., Khan, S., Ali, S.K.
}

\begin{abstract}
Background: Postgraduate medical training is a stressful experience for both male and female doctors but previous studies have shown that stress might be more prevalent amongst female residents. Since women make up $70-80 \%$ of medical graduates in Pakistan we conducted this study to determine the prevalence of stress among female residents during postgraduate training and identify the most common stressors.
\end{abstract}

Methodology: All female residents enrolled in postgraduate training programmes at the Aga Khan University meeting the inclusion criteria were recruited and informed written consent was obtained. Job Stress Inventory (JSI) was used to identify symptoms and sources of job stress. A cut-off value of $>25$ was used to indicate job stress.

Results: A total of 154 female residents met the inclusion criteria. The response rate of the survey was $77 \%$. Sixty one residents scored 26 or more on the JSI, indicating the presence of job stress. The three most common causes cited for job stress were, lack of control, environmental factors and workplace politics.

Conclusion: Our study indicates a high prevalence of stress among female residents, independent of the marital status, number of children, the chosen specialty or the level of training. We suggest that programme directors and supervising faculty acknowledge the need for change in the training programmes refraining from favoritism and the need for politics towards constructive feedback based on merit and hard work and allow the residents to have more control over their working environment.

Key Words: postgraduate residency training

\section{Introduction}

Postgraduate medical training is a stressful experience for both male and female doctors (Nesbitt, 1988), but women tend to report higher levels of stress reaction during residency than men (Butterfield, 1988; Hughes et al., 1991) These stressors have been reported to lead to depression (Butterfield, 1988; Hsu et al., 1987), burn-out (Dyer, 1994), anger and irritability (Scneider \& Phillips, 1993) anxiety (Hughes et al., 1992), substance abuse (Hughes et al., 1991) and drop out. Most of this data is from western countries and as stress maybe influenced by unique cultural factors, the level and sources of stress may be different in different regions.

Aga Khan University Hospital,

Karachi, Pakistan

Corresponding Author:

Dr. Madiha Hashmi

Aga Khan University, Stadium Road, 3500

Karachi 74800, Pakistan

Email: madiha.hashmi@aku.edu
Pakistan is perceived to be a conservative society and in order to pursue their medical careers, women doctors have to overcome several prejudices and pressures. Since women make up $70-80 \%$ of medical graduates in Pakistan (Rebecca, 2013; Zofeen, 2010) we conducted this study to explore workplace stress in female residents and identify the most common sources of stress based on the Job Stress Inventory (JSI).

\section{Methods}

This cross-sectional study was conducted at the Aga Khan University during 2012-2013. Ethics committee approval was obtained prior to starting the survey and Associate Dean Postgraduate Medical Education (PGME) was informed. All female residents enrolled in the post graduate training programmes were recruited. Informed written consent was obtained from all participants. Exclusion criteria were trainees who were enrolled in fellowship programmes, those on leave or placed in 
external elective rotations outside the main campus.

The JSI was used to identify symptoms and sources of job stress. A hard copy of the JSI was sent to all the participants along with a letter explaining the purpose of this study. We aimed for a response rate of $75 \%$. All survey forms returned by the residents were collected by the principal investigator and the data was coded to protect the identity of the participants. Data was entered on to SPSS by a research officer and double checked. Cross-tabulation and frequency were computed to analyze symptoms and sources of job stress by using statistical software (SPSS Inc., Chicago, IL version-19). A cut-off value of 26 or above was used to indicate job stress. Cronbach's alpha was computed to assess the reliability of the questionnaire.

\section{Results}

One hundred and fifty four women residents met the inclusion criteria. Completed questionnaires were returned by one hundred and nineteen subjects ( $77.27 \%)$.

\section{Characteristics of the residents}

As shown in Table 1, residents were divided into three groups based on specialty; Medicine and allied specialties, Surgery and allied specialties and the RAP group which included Radiology, Anaesthesia and Pathology. The majority of $(n=61,51 \%)$ residents belonged to Medicine and allied specialties were junior residents (in the first 2 years of training) while seventy two $(60.5 \%)$ were senior residents, i.e. in the third, fourth and final year of training. Forty-nine (41\%) were married and $56 \%$ of the married residents had not yet started a family. Thirty two percent had one child, $8 \%$ had two children and $4 \%$ had more than two.

\section{Job Stress}

The questions used to identify the symptoms of job stress had a Cronbach's alpha of 0.92 . Three questions had Cronbach's alpha less than 0.50 and removing them did not improve the reliability to more than 0.92 . The mean JSI score of the whole group was 28.13 (2.0070.00 ; SD 14.07). With the recommended cutoff value of 26 on the $\mathrm{JSI}$ tool, the estimated prevalence of job stress was $51 \%$.

Table 1: Representation of various residency programmes

\begin{tabular}{lccc}
\hline Specialty Group & $\begin{array}{c}\text { No of residents } \\
\mathbf{n} \mathbf{n}\end{array}$ & $\begin{array}{c}\text { No of residents who } \\
\text { completed the survey } \\
\mathbf{=} \mathbf{n}(\%)\end{array}$ & $\begin{array}{c}\text { Response rate } \\
(\%)\end{array}$ \\
\hline Medicine \& Allied & 77 & $61(51.2 \%)$ & $79.22 \%$ \\
Surgery \& Allied & 32 & $18(15.1 \%)$ & $56.25 \%$ \\
Radiology, Anaesthesia \& & 45 & $40(33.6 \%)$ & $88.88 \%$ \\
Pathology & $\mathbf{1 5 4}$ & $\mathbf{1 1 9}$ & $\mathbf{7 7 . 2 7 \%}$ \\
Total & & &
\end{tabular}

Table: 2 Relationship of resident characteristics to mean JSI score

\begin{tabular}{lccc}
\hline & Mean (S.D) & p=value & \\
\hline PGME programme & & & \\
Medicine and Allied & $28.93(14.08)$ & 0.64 & NS \\
Surgery and Allied & $29.86(14.61)$ & & \\
Radiology, anaesthesia and pathology & $26.62(14.07)$ & & \\
Residency & & & \\
Junior & $32.52(15.32)$ & 0.87 & NS \\
Senior & $26.00(12.32)$ & & \\
Marital status & & & \\
Single & $27.96(14.33)$ & 0.46 & NS \\
Married & $29.63(13.51)$ & & \\
$\quad$ & & & \\
No. of children & $27.37(10.82)$ & 0.62 & NS \\
Single child & $33.00(16.02)$ & & \\
Two children & $24.50(6.36)$ & & \\
Three children &
\end{tabular}


No statistically significant difference was observed in the mean JSI score amongst residents in the three specialty groups, senior or junior, married or single and number of offsprings the married residents had ( $p$ value 0.64 , $0.87,0.46,0.62$ respectively). This is shown in Table 2.

\section{Sources of job stress}

The overall reliability of the scores to identify sources of job stress on the JSI was 0.94. Table 3 shows the frequency of responses grouped into two categories, i.e. (never + occasionally) and (somewhat often + frequently + almost always). The three most common causes cited for job stress were lack of control ("I feel trapped in a situation without any real options", "I am unable to influence decisions that affect me", and "there are a lot of requirements that get in the way of my doing certain tasks"), environmental factors ("I have to deal with many little hassles") and workplace politics ("I sense that popularity and politics are more important than performance").

Table 3: Frequencies of responses to items indicating the sources of job stress

\begin{tabular}{|c|c|c|c|}
\hline $\begin{array}{l}\text { Sources of } \\
\text { stress }\end{array}$ & Items & $\begin{array}{c}\text { Never + } \\
\text { Occasionally } \\
\text { n (\%) }\end{array}$ & $\begin{array}{c}\text { Somewhat } \\
\text { often + } \\
\text { Frequently + } \\
\text { Almost always } \\
\mathbf{n}(\%)\end{array}$ \\
\hline \multirow{3}{*}{ Lack of Control } & I lack the authority to carry out certain responsibilities & $83(70.9 \%)$ & $34(29.1 \%)$ \\
\hline & I feel trapped in a situation without any real options & $66(56.4 \%)$ & $51(43.6 \%)$ \\
\hline & I am unable to influence decisions that affect me & $62(53.0 \%)$ & $55(47.0 \%)$ \\
\hline \multirow[t]{2}{*}{0.79} & $\begin{array}{l}\text { There are a lot of requirements that get in the way of } \\
\text { my doing certain tasks }\end{array}$ & $44(37.6 \%)$ & $73(62.4 \%)$ \\
\hline & I can't solve the problems assigned to me & $97(82.9 \%)$ & $20(17.1 \%)$ \\
\hline \multirow{3}{*}{ Information gap } & I am unsure about the responsibilities of my job & $94(80.3 \%)$ & $23(19.7 \%)$ \\
\hline & $\begin{array}{l}\text { I don't have enough information to carry out certain } \\
\text { tasks }\end{array}$ & $94(80.3 \%)$ & $23(19.7 \%)$ \\
\hline & $\begin{array}{l}\text { I am under qualified for certain tasks I'm expected to } \\
\text { do }\end{array}$ & $97(82.9 \%)$ & $20(17.1 \%)$ \\
\hline \multirow[t]{3}{*}{0.68} & Others I work with are not clear about what I do & $93(79.5 \%)$ & $24(20.5 \%)$ \\
\hline & $\begin{array}{l}\text { I don't understand the criteria used to evaluate my } \\
\text { performance }\end{array}$ & $75(64.1 \%)$ & $42(35.9 \%)$ \\
\hline & $\begin{array}{l}\text { There is no relationship between how I perform and } \\
\text { how I am rated }\end{array}$ & $72(61.5 \%)$ & $45(38.5 \%)$ \\
\hline \multirow[t]{2}{*}{$\begin{array}{l}\text { Cause and } \\
\text { effect }\end{array}$} & $\begin{array}{l}\text { I sense that popularity and politics are more important } \\
\text { than performance }\end{array}$ & $46(39.3)$ & $71(60.7 \%)$ \\
\hline & $\begin{array}{l}\text { I don't know what my supervisor thinks of my } \\
\text { performance }\end{array}$ & $71(60.7 \%)$ & $46(39.3 \%)$ \\
\hline \multirow[t]{2}{*}{0.79} & $\begin{array}{l}\text { I don't know what I am doing right and what I am doing } \\
\text { wrong }\end{array}$ & $88(75.2 \%)$ & $29(24.8 \%)$ \\
\hline & $\begin{array}{l}\text { If I give suggestions, my supervisor does not include } \\
\text { them }\end{array}$ & $88(75.2 \%)$ & $29(24.8 \%)$ \\
\hline \multirow{3}{*}{ Conflicts } & I am expected to satisfy conflicting needs & $73(62.4 \%)$ & $44(37.6 \%)$ \\
\hline & I disagree with co-workers & $91(77.8 \%)$ & $26(22.2 \%)$ \\
\hline & I disagree with my supervisor & $96(82.1 \%)$ & $21(17.9 \%)$ \\
\hline \multirow[t]{3}{*}{0.73} & I am caught in the middle & $92(78.6 \%)$ & $25(21.4 \%)$ \\
\hline & I can't get what I need to get the job done & $94(80.3 \%)$ & $23(19.7 \%)$ \\
\hline & $\begin{array}{l}\text { I feel pessimistic about opportunities for advancement } \\
\text { or growth in my job }\end{array}$ & $79(67.5 \%)$ & $38(32.5 \%)$ \\
\hline \multirow{4}{*}{$\begin{array}{c}\text { Alienation } \\
0.79\end{array}$} & My supervisor or boss is critical & $85(72.6 \%)$ & $32(27.4 \%)$ \\
\hline & I feel unaccepted by the people I work with & $96(82.1 \%)$ & $21(17.9 \%)$ \\
\hline & My good work is not noticed or appreciated & $68(58.1 \%)$ & $49(41.9 \%)$ \\
\hline & My progress on the job seems less than it could be & $75(64.1 \%)$ & $42(35.9 \%)$ \\
\hline
\end{tabular}




\begin{tabular}{|c|c|c|c|}
\hline \multirow{3}{*}{ Overload } & I experience little meaning in my work & $82(70.1 \%)$ & $35(29.9 \%)$ \\
\hline & I feel unsupported by my co-workers or boss & $80(68.4 \%)$ & $37(31.6 \%)$ \\
\hline & My values seem at odds with those of management & $82(70.1 \%)$ & $35(29.9 \%)$ \\
\hline \multirow{2}{*}{0.86} & The organization seems insensitive to my individuality & 74(63.2\%) & $43(36.8 \%)$ \\
\hline & $\begin{array}{l}\text { I find I cannot by myself at work because i feel } \\
\text { different from my co-workers }\end{array}$ & $91(77.8 \%)$ & $26(22.2 \%)$ \\
\hline \multirow{3}{*}{ Under load } & I have too little to do & $109(93.2 \%)$ & $8(6.8 \%)$ \\
\hline & I feel overqualified for the work I actually do & $105(89.7 \%)$ & $12(10.3 \%)$ \\
\hline & My work is not challenging & $100(85.5 \%)$ & $17(14.5 \%)$ \\
\hline \multirow[t]{2}{*}{0.68} & Most of my work is very routine & $82(70.1 \%)$ & $35(29.9 \%)$ \\
\hline & I miss contact with people in my job & $72(61.5 \%)$ & $45(38.5 \%)$ \\
\hline \multirow{5}{*}{ Environment } & I find my work environment & $82(70.1 \%)$ & $35(29.9 \%)$ \\
\hline & I lack the privacy I need to concentrate on my work & $91(77.8 \%)$ & $26(22.2 \%)$ \\
\hline & Some aspects of my environment seem hazardous & $78(66.7 \%)$ & $39(33.3 \%)$ \\
\hline & I have too much or too little contact with people & $72(61.5 \%)$ & $45(38.5 \%)$ \\
\hline & I have to deal with many little hassles & $67(57.3 \%)$ & $50(42.7 \%)$ \\
\hline \multirow{5}{*}{ Value conflict } & I must do things that are against my better judgment & $86(73.5 \%)$ & $31(26.5 \%)$ \\
\hline & I must make compromises with my values & $78(66.7 \%)$ & $39(33.3 \%)$ \\
\hline & My family and friends do not respect what I do & $99(84.6 \%)$ & $18(15.4 \%)$ \\
\hline & $\begin{array}{l}\text { I observe my co-workers doing things that I don't } \\
\text { approve of }\end{array}$ & $86(73.5 \%$ & $31(26.5 \%)$ \\
\hline & $\begin{array}{l}\text { The organization that I work for pressures employees } \\
\text { to do things that are unethical or unsafe }\end{array}$ & $97(82.9)$ & $20(17.1 \%)$ \\
\hline
\end{tabular}

\section{Discussion}

While women entering medical profession faced an uphill struggle in the nineteenth century (Gunning, 1996), the twenty first century is seeing a feminization of medicine (Brian, 2008). The percentage of female medical graduates in the United States in 2011 was 48.3\% (Barzansky \& Etzel, 2011). According to Royal College of Physicians, at least $50 \%$ of new UK medical graduates have been female for a decade, rising to over $60 \%$ between 2007 and 2009 (Elston, 2009). In Pakistan $70-80 \%$ of medical students are females (Rebecca, 2013; Zofeen, 2010). Despite the increased enrollment of women in medical schools, the medical workforce in Pakistan is severely lopsided. There are 135,212 doctors registered with the Pakistan Medical \& Dental Council (PM \& DC) of which only $45 \%(60,313)$ are females, and the number of female specialist doctors is even smaller i.e. $26 \%(7,678)$ [PMDC 30th June, 2013]. Results of this study show a high prevalence of stress amongst female postgraduate female residents working in a private medical university in Pakistan and this might be a contributing factor to lessen female specialists in the country. However this level of stress is comparable to the physicians' stress reported in previous studies, i.e. $48 \%$ doctors including trainees, general practitioners and consultants graded job stress from high to very high in a study conducted at the same institution in 2002, with higher levels of stress reported by females (Khuwaja et al., 2004). Firth-Cozen reported that $50 \%$ of junior house officers exhibited emotional distress (Firth-Cozens, 1987) and Caplan reported that about half of senior medical staff suffered from high levels of stress and anxiety (Caplan, 1994).

Women are underrepresented in most surgical fields globally (Allen, 1989; Maheux et al., 1989; Wakeford et al., 1989) due to the female physician's awareness of the competing demands made on her time by career, marriage and children (McCue, 1985). This was also seen in our survey where, Medicine was the career choice of $51 \%$ residents, followed by the RAP group (34\%), with only $15 \%$ of women doctors taking up surgery. The surgical specialty is perceived to be more stressful but in our survey though the surgical residents had the highest mean JSI score, this was not statistically different from medicine and the RAP group. However the poor response rate $(56.25 \%)$ from residents from the surgical and allied specialties might have skewed the results. 
Junior house officers have been identified by North American authors to be most vulnerable to stress (Small, 1981; Ziegher et al., 1984; Ford, 1983; Mazie, 1985). In our survey the junior residents (year 1 and 2) had a higher mean JSI score as compared to the senior residents (year 3, 4 \& 5) but this did not reach statistical significance.

We commenced the study with the assumption that married women residents with multiple personal and professional demands will be more at risk of experiencing job stress, but the results showed that there was no statistical significance between the mean JSI scores of married and single residents. Several studies have similarly found that marriage and strong social contacts reduce the perception of stress (Landau et al., 1986; Kelner, \& Rosenthal, 1986; Bickel, 2000). Residency is the most common period for female physicians to have their first child (Philips, 2000). In our survey $56 \%$ of the married residents had not started a family. Residents with two children were the most stressed but this was not statistically significant.

Job-related stress, career dissatisfaction and psychological distress are greatest when high levels of demands are placed on the physician while providing little individual control over work and little autonomous decision-making power (Amick, 1998; Mumford, 1983). This study has also highlighted the fact that lack of control, having to deal with small hassles, and politics and favoritism are the most prevalent causative factors of stress among the female residents.

In an editorial Mumford stressed that educators in medical disciplines should make changes in the training system after identifying "who" specifically is vulnerable and "what" specifically is harmful to medical training (Mumford, 1983). We have identified that women residents in a major teaching hospital are at risk of stress and lack of control over environment, politics and favoritism at the workplace and those are harmful aspects of their training. We plan to share the findings of this survey with our postgraduate medical education committee. We suggest that programme directors and supervising faculty should acknowledge the need for change in the training programme, refraining from favoritism and the need for politics and more towards constructive feedback based on merit and hard work instead of popularity. Strategies focused towards reduction and prevention of stress could include formal education of the residents about stresses inherent in the training programmes, workshops directed at managing stress and gripe sessions of residents and interested faculty to openly discuss their concerns and feelings.

There are some limitations to this study. This was a single center study at a private university hospital that attracts high-achievers; career oriented, motivated female doctors and may not reflect the issues faced by female residents working in other institutions or public sector hospitals. There are limitations to the tool that we used to measure stress. The JSI identifies presence of job stress and sources of stress related to the workplace, but does not provide measures of work stress unique to women. We feel that there is a further need to explore sources of stress unique to women physicians working in our conservative society utilizing an open-ended qualitative methodology.

\section{Conclusion}

This study showed that a high percentage of female residents suffer from stress (51\%). These results were not dependent on year of residency programme, marital status or chosen specialty.

\section{Acknowledgements}

Ms. Feroza Nazir, Research Associate, Department of Anaesthesiology, Aga Khan University.

\section{References}

Allen, D.I. (1989) Women in medical specialty societies: An update, Journal of American Medical Association, 262, 24, pp. 3439-3443.

Amick, B.C., Kawachi, I., Coakley, E.H., Levine, S. \& Colditz, A. (1998) Relationship of job strain and iso-strain to health status in a cohort of women in the United States, Scandinavian Journal of Work, Environment \& Health, 24, 1, pp. 54-61.

Barzansky, B. \& Etzel, S.I. (2011) Medical Schools in the United States, 2010-2011, Journal of American Medical Association, 306, 9, pp. 1007-1014.

Bickel, J. (2000) Women in Medicine: Getting in, Growing, and Advancing, Thousand Oaks, CA: Sage Publications.

Brian, M. (2008) Are there too many female medical graduates? British Medical Journal, 336, pp. 336748.

Butterfield, P.S. (1988) The stress of residency, A review of the literature, Archives of Internal Medicine, 148, 6, pp. 1428-1435.

Caplan, R.P. (1994) Stress, anxiety, and depression in hospital consultants, general practitioners, and senior health service managers, British Medical Journal, 309, 6964, pp. 1261-1263. 
Dyer, K.A. (1994) Toxic intern syndrome, Western Journal of Medicine,160, 4, pp. 378-379.

Elston, M.A. (2009) Women and medicine: The future: Summary of findings from Royal College of Physicians Research [Online] Available at: https://www.rcr.ac.uk/sites/default/files/RCPWom en_\%20in_\%20Medicine_\%20Report.pdf [Accessed: October, 2014 ]

Ford, G.V. (1983) Emotional distress in internship and residency: A questionnaire study, Psychiatric Medicine, 1, 2, pp. 143-150.

Firth-Cozens, J. (1987) Emotional distress in junior house officers, British Medical Journal, 295, 6597, pp. 533-536.

Gunning, M. (1996), A brief History of women in Surgery, The Royal College of Surgeons of England LIBRARY, [Online] 26th February. Available from: https://www.rcseng.ac.uk [Accessed: 24th August, 2013].

Hsu, K. \& Marshall, V. (1987) Prevalence of depression and distress in a large sample of Canadian residents, interns, and fellows. American Journal of Psychiatry, 144, 12, pp. 15611566.

Hughes, P., Conrad, S., Baldwin, D., Storr, C. \& Sheehan, D. (1991) Resident physician substance abuse in the United States, Journal of American Medical Association, 265. pp. 2069-2073.

Hughes, P.H., Baldwin, D.C., Sheehan, D.V., Conrad, S. \& Storr, C.L. (1992) Resident physician substance use, by specialty, American Journal of Psychiatry, 149, 10, pp. 1348-1347.

Kelner, M. \& Rosenthal, C. (1986) Postgraduate medical training, stress, and marriage, The Canadian Journal of Psychiatry, 31, 1, pp. 22-24.

Khuwaja, A.K., Qureshi, R., Andrades, M., Fatmi, Z. \& Khuwaja, N.K. (2004) Comparison of job satisfaction and stress among male and female doctors in the teaching hospitals of Karachi, Journal of Ayub Medical College, Abbottabad, 16, 1, pp. 23-27.

Landau, C., Hall, S., Wartman, S.A. \& Macko, M.B. (1986) Stress in social and family relationships during the medical residency, Academic Medicine, 61, 8, pp. 654-660.

Mazie, B. (1985) Job stress, psychological health, and social support of family practice residents, Academic Medicine, 60, 12, pp. 935-941.
McCue, J.D. (1985) The distress of internship. Causes and prevention, The New England Journal of Medicine, 312, pp. 449-452.

Moaheux, B., Dufort, F., Lambert, J. \& Levesque, A. (1989) The professional attitudes and practice characteristics of male and female specialists, Journal of the American Medical Women's Association, 44, 5, pp. 154-158.

Mumford, E. (1983) Stress in the medical career, Academic Medicine, 58, 5, pp. 436-434.

Nesbitt, D. (1988). Stress and impairment during residency training: strategies for reduction, identification, and management, Annals of Internal Medicine, 109, 2, pp.154-161.

Pakistan Medical and Dental Council [Online] Available at: http://www.pmdc.org.pk/Home /tabid /36/Defu.aspx [Accessed: October, 2014].

Philips, S.P. (2000) Parenting, puppies and practice. Juggling and gender in medicine, Canadian Medical Association Journal, 162, 5, pp. 663-664.

Rebecca, S. (2013) Pakistan's Medical SchoolsWhere The Women Rule, Associated Press News [Online] 19th April, Available at: http://bigstory.ap.org [Accessed: 3rd October 2013].

Scneider, S.E. \& Phillips, W.M. (1993) Depression and anxiety in medical, surgical and paediatric interns, Psychological Reports, 72, 3, pp. 1145114.

Small, G.W. (1981) House officer stress syndrome, Psychosomatics, 22. pp. 860-869.

Verlander, G. (2004) Female Physicians: Balancing Career and Family, Academic Psychiatry, 28, 4, pp. 331-336.

Wakeford, R.E \& Warren, V.J. (1989) Women doctors' career choice and commitment to medicine: Implications for general practice. Journal of the Royal College of General Practitioners, 39, pp. 91-95.

Ziegher, J.L., Kanas, N., Struss, W.M. \& Bennet, N.E. (1984) A stress discussion group for medical interns, Academic Medicine, 59, 3, pp. 205-207.

Zofeen, E. (2010) When the Doors are Open, But Women Choose to Stay Away, Inter Press Service News Agency [Online] 21st September. Available at: http://www.ipsnews.net [Accessed: 18th May 2012]. 